\title{
Computer Assisted Language Testing: On the Efficacy of Web-based Approach in the Instruction of Elementary Learners of English
}

\author{
Maryam Soleimani ${ }^{1} \&$ Shima Gahhari ${ }^{2}$ \\ ${ }^{1}$ University of Tabriz, Tabriz, Iran \\ ${ }^{2}$ Ferdosi University of Mashhad, Mashhad, Iran \\ Correspondence: Maryam Soleimani, University of Tabriz, Tabriz, Iran. Tel: 914-140-2440. E-mail: \\ maryam.soleimani@yahoo.com
}

\author{
Received: May 29, 2012 Accepted: June 25, 2012 Online Published: July 25, 2012 \\ doi:10.5539/elt.v5n9p66 URL: http://dx.doi.org/10.5539/elt.v5n9p66
}

\begin{abstract}
In this study the effectiveness and efficacy of e- learning was evaluated through a web based approach. Two classes of elementary learners of English were selected for this study, one class received a six month instruction through the typical twice a week classes and the other one was instructed through internet, in other words, the first class did not use any web based materials such as chat rooms, emails, etc ,however, the second class did not attend classes at all except for monthly meetings with the instructor in order to unravel some loopholes they encountered in dealing with internet and e-learning. They simply interacted with their instructor through internet by emails and chat rooms, this group was taught simply by internet, for example, they mailed their writings to their teacher once a weak and the instructor gave feedback through e-mail, they also were assigned to chat every night with their classmates or native speakers and report the result to their instructor and so on. The final results revealed that the web based class outperformed the traditional class in writing, and reading comprehension, but the results were in favor of the traditional group regarding speaking performance and structural knowledge.
\end{abstract}

Keywords: web-based instruction, elementary learners, reading, writing, speaking, structure

\section{Introduction}

As Lee (2000) points out, web presents a venue replete with authentic daily materials apt for instruction, it also gives itself well into communicative language teaching premises and principles in as much as web is inundated with authentic, genuine, and communicative real-life materials conducive to the $21^{\text {st }}$ century communicative language teaching and learning objectives. Beltz, (2003) and Thorne (2003) believe that language teachers can use internet for cultural awareness purposes in classroom, therefore, it helps learners get exposed to language and culture simultaneously. Wilson (1995) maintains that teachers utilize internet in order to access libraries all over the world, to share lesson plans, to communicate with students' parents, and to download current information beneficial for classroom use. In this study, it is attempted to compare the differential effects of two approaches, namely, web based and traditional in the instruction of elementary learners of English.

\section{Literature Review}

As put by Uzunboylu (2005), W.W.W Is a novel technology utilized as the facilitator of communication and instruction, the universities concomitantly took the advantage of this technology immediately and embarked on using web as the medium of instruction regardless of distance and time (Isman \& Dabaj, 2005). The advantage of using multimedia according to Zimmer (2003) is to relate information efficiently to all students and to keep them intrigued. Many universities and institutions throughout the world are bending over backward trying to integrate web based instruction into their courses and curriculum designs. A multitude of colleges and language institutes, too, have amalgamated web based instruction as a regular part of their course objectives and broad curriculum goals.

Tanyeli (2009) showed that law students were better at web based learning compared to the traditional control group. Delfino and Manca (2006) investigated how the participants of a learning environment used written language in a creative way through the spontaneous use of figurative language, their results divulged that participants were more inclined to use figurative language when critical or meaningful events happened. Web based instruction has also been used to assess library use by students and to investigate how it may ameliorate 
library use by learners. Meer (2000) explored the creative ways libraries used web for instruction and to support faculty use of web for teaching. Remote use of libraries according to his results increased resulting in increased use of libraries off-site. In a study by Emurian (2004) seventeen graduate students in two classes participated in a web based programmed instruction tutoring system, the results revealed that programmed instruction can produce problem solving skills and can foster student confidence. A great number of researches have been conducted in order to simulate the classroom experiences in real-time two way interactions between teacher and students (Shi et al., 2003).

Use of Web based instruction has been on the rise compared to traditional approaches in a plethora of studies (Eskenazi, 1999; Nelson \& Oliver, 1999; O'Dowd, 2003; Toyoda \& Harrison, 2002; and Warner, 2004). The majority of studies on web-based instruction have revealed the efficacy of this approach in learning and teaching students compared to traditional classes. Web based instruction is also interesting and motivating and it is more in harmony with the growing body of internet based education which is on rapid rise throughout the world.

In this study, there is an attempt to elucidate the efficacy of web based instruction on assisting the elementary learners' acquisition of English structures, reading comprehension, writing, and speaking. This study will leave no stone unturned in attempting to explore the role of internet and web in facilitating and ameliorating language instruction. A distinct feature of the present study is its attempt to investigate the role of web in learning components of language, that is, structure, reading, writing, and speaking.

\section{Method}

\subsection{Participants}

The participants of this study comprised 40 elementary learners of English in a language institute. There were 20 participants in the experimental group and 20 in the control group. The average age for experimental group was 15 and for the control group was 16. The learners had not attended any English classes before and they were all given a placement test by the institute, therefore, they were all in almost the same competency level, however, a pre-test was given to these learners in order to make sure that the participants were all at the same competency level.

\subsection{Materials}

The materials used in this study were 1) the learners' textbook which they covered in 3 terms, 2) a pre-test which was taken out of the text book they were supposed to cover during the terms,3) a post-test which was also a parallel form of the pretest which was a form of achievement test given to these learners.

\subsection{Procedure}

The experimental group received instruction for six months only through emails and chatting with the teacher or fellow learners or native speakers, they were instructed on how to use chat rooms and email in order to communicate with their teacher, fellow learners and foreigners especially native speakers. The participants were supposed to report every session what they had done through web and teacher gave feedback in order to improve the participants' use of web for learning purposes. The control group, on the other hand, received the same instruction for the text book during 6 months, with the only difference being that the participants in this group only received instruction through typical traditional classes, in other words, there was no web based material or instruction as to how to use web. To put it in a nut shell, the only difference between experimental and the control group was web-based instruction for the experimental group.

\section{Results}

The descriptive statistics of gained-scores of two teaching types (web-based and traditional) for reading, writing, speaking, and structure are reported in Table 1.

Table 1. Descriptive statistics of web-based and traditional types for reading, writing, speaking, and structure

\begin{tabular}{|c|c|c|c|c|}
\hline groups & number & mean & Std. Deviation & Std. error mean \\
\hline Reading(web-based) & 20 & 28.20 & 8.52 & 1.9 \\
\hline Reading(traditional) & 20 & 17.90 & 6.12 & 1.3 \\
\hline Writing(web-based) & 20 & 31.10 & 7.29 & 1.6 \\
\hline Writing(traditional) & 20 & 16.95 & 3.90 & 0.8 \\
\hline Speaking(web-based) & 20 & 16.35 & 7.45 & 1.6 \\
\hline Speaking(traditional) & 20 & 34.40 & 5.69 & 1.2 \\
\hline Structure(web-based) & 20 & 9.60 & 5.80 & 1.2 \\
\hline Structure(traditional) & 20 & 35.75 & 6.47 & 1.4 \\
\hline
\end{tabular}


Table 2. Comparison of web-based and traditional types of teaching reading

\begin{tabular}{|c|c|c|c|c|c|}
\hline \multirow[t]{2}{*}{ reading } & \multicolumn{2}{|c|}{$\begin{array}{l}\text { Levene's test for } \\
\text { equality of variance }\end{array}$} & \multicolumn{3}{|c|}{ t-test for equality of means } \\
\hline & $\mathrm{f}$ & sig & $\mathrm{t}$ & df & $\begin{array}{l}\text { Sig.(2) } \\
\text { tailed) } \\
\end{array}$ \\
\hline $\begin{array}{l}\text { Equal variance } \\
\text { assumed }\end{array}$ & 1.35 & .252 & $4.39^{* \pi}$ & 38 & .05 \\
\hline
\end{tabular}

\section{$P \quad .05, d f=38$}

In table 2, the results of the $t$-test in comparison between two types of teaching reading (web-based and traditional) are reported. The result of the t-test indicates that there is a significant difference $\left(\mathrm{M}_{\text {web-based }}=28.20\right.$, $\left.\mathrm{M}_{\text {traditional }}=17.90\right)$ between students in web-based group and in traditional group $(t(\mathrm{df}=38)=4.39 ; p \quad .05)$.

Successively in table 3 the results indicate that students in web-based group outperform $\left(\mathrm{M}_{\mathrm{web}-\mathrm{based}}=31.10, \mathrm{M}\right.$ traditional $=16.95)$ learners in traditional ones $(t(38)=7.64 ; p \quad .05)$

Table 3. Comparison of web-based and traditional types of teaching writing

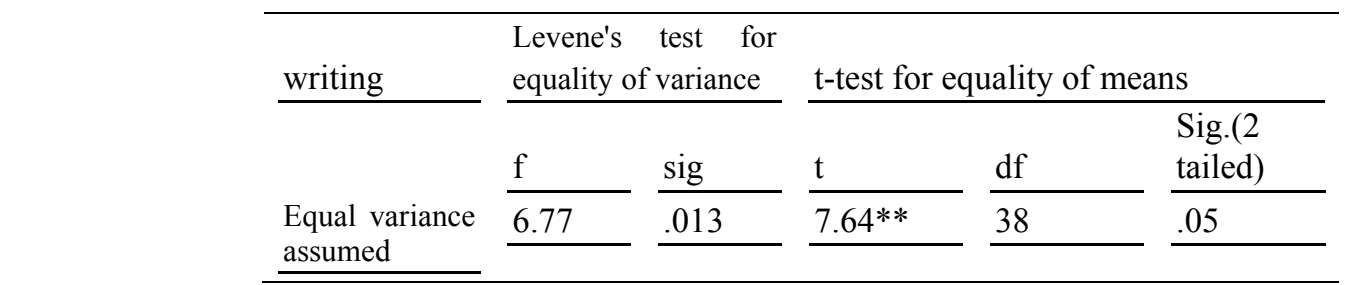

$p \quad .05 d f=38$

In similar vein, table 4 shows the findings of the two groups in teaching structure, traditionally taught learners made significant gains on post-test $\left(\mathrm{M}_{\text {web-based }}=9.6, \mathrm{M}_{\text {traditional }}=35.75, t(38)=-13.44, p \quad .05\right)$.

Table 4. Comparison of web-based and traditional types of teaching structure

\begin{tabular}{|c|c|c|c|c|}
\hline structure & $\begin{array}{l}\text { Levene's test for } \\
\text { equality of variance }\end{array}$ & $\mathrm{t}$-test for $\mathrm{e}$ & Ialit & \\
\hline & sig & $\mathrm{t}$ & df & $\begin{array}{l}\text { Sig.(2 } \\
\text { tailed) }\end{array}$ \\
\hline $\begin{array}{l}\text { Equal variance } \\
\text { assumed }\end{array}$ & .21 & $-13.44^{* *}$ & 38 & .05 \\
\hline
\end{tabular}

$p \quad .05 d f=38$

Comparisons of gained score results of speaking tests in table 5 indicated the superiority of traditional way of teaching of this skill $\left(\mathrm{M}_{\text {web-based }}=16.35, \mathrm{M}_{\text {traditional }}=34.40, t(38)=-8.60, p \quad .05\right)$.

Table 5. Comparison of web-based and traditional types of teaching speaking

\begin{tabular}{|c|c|c|c|c|c|}
\hline \multirow[t]{2}{*}{ speaking } & \multicolumn{2}{|c|}{$\begin{array}{l}\text { Levene's test for } \\
\text { equality of variance }\end{array}$} & \multicolumn{3}{|c|}{ t-test for equality of means } \\
\hline & $\underline{f}$ & $\underline{\operatorname{sig}}$ & $\underline{\mathrm{t}}$ & $\mathrm{df}$ & $\begin{array}{l}\text { Sig.(2) } \\
\text { tailed) }\end{array}$ \\
\hline $\begin{array}{l}\text { Equal variance } \\
\text { assumed }\end{array}$ & 2.71 & .10 & $-8.60 * *$ & 38 & .05 \\
\hline
\end{tabular}

\section{p .05 $d f=38$}

\section{Discussion}

As was perspicuous in the results section, the traditional group outperformed the web based group in speaking and structural knowledge, however, in case of reading and writing skills, the web based group performed far better. 
Delfino and Manca (2006) showed that participants used figurative language in a creative way in their writings, in this study too, participants of the web based group revealed a better performance in writing compared to the traditional group. Regarding reading comprehension, too, the participants of the web based group outperformed the traditional group. These findings might be explicable in the light of the fact that web based classes were mostly taught through reading passages that the teacher sent to participants through e-mail, and the other passages were taken from internet. The majority of the activities in the web based group were reading and writing activities since the interaction between the teacher and the learners mostly occurred through reading and writing, for instance, the participants wrote passages and mailed to the teacher. The teacher corrected the passages and sent back the papers to the learners. Learners were also assigned some reading passages about which they were supposed to write a summary and mail to the teacher which were in time corrected and resent to the participants.

The question that is a little evasive and difficult to answer is why traditional group outperformed the web based group in terms of structures and speaking performance. One explanation might be that since in the traditional class learners attended the class twice a week and each class was held for 90 minutes, the participants had enough time to talk and this free discussion itself stimulated the emergence of speaking ability. However, in the web based group the participants had little opportunity to communicate and there was meager learner-learner or teacher-learner interaction. Concerning the structural knowledge in which web based group did not excel the traditional group, some points should be taken into consideration. In the traditional class which was a typical language class, there was some attention to forms, sometimes as post speaking or reading activities, sometimes as direct grammatical explanations by the teacher and so forth. But in the web based group learners received feedback on their grammatical accuracy only through feedback given on their writings, and the point to consider is that this feedback was not in direct interactional form like inside class feedback which is face to face. This might explain why traditional group outperformed the web based group in structural knowledge.

The results of the present study point out the fact that web based language teaching and learning is not necessarily the best approach to teach foreign languages and as the famous saying goes, whatever is new is not necessarily better. This should not be interpreted as the uselessness of web based approaches or a criticism against these approaches. What this piece of research shows is that web based approaches might not be as useful for the teaching and learning of all components and sub components of language. What this research recommends is that the best and most expedient way might be an amalgamation of both web based and traditional approaches to the teaching and learning of foreign languages.

\section{References}

Beltz, J. A. (2003). Linguistic perspectives on the development of intercultural competence in telecollaboration. Language Learning \& Technology, 7(2), 68-117. Retrieved September 17, 2004, from http://lt.msu.edu/vol7num2/belz/default.html

Delfino, \& Manca. (2006). The expression of social presence through the use of figurative language in a web-based learning environment. Computers in Human Behavior, 23, (2007), 2190-221.

Emurian, H. (2004). Web-based programmed instruction: evidence of rule-governed learning. Computers in Human Behavior, 21, (2005), 893-915.

Eskenazi, M. (1999). Using automatic speech processing for foreign language pronunciation tutoring: Some issues and a prototype. Language Learning \& Technology, 2(2), 62-76. Retrieved February 9, 2006, from http://lt.msu.edu/ vol2num2/article3/S

Isman, A., \& Dabaj, D. (2005). Diffusion of Distance Education in North Cyprus. Turkish Online Journal of Distance Education.

Lee, L. (2000). Using Internet to enhance foreign language teaching and learning. Retrieved June 15, 2007, from http://www.unh.edu/spanish/lina/internet1.html

Nelson, T., \& Oliver, W. (1999). Murder on the Internet. CALICO Journal, 17(1), 101-114.

O'Dowd, R. (2003). Understanding the "other side": Intercultural learning in a Spanish-English e-mail exchange. Language Learning \& Technology, 7(2), 118-144. Retrieved September 24, 2004, from http://lt.msu.edu/vol7num2/odowd/default.html

Patricia Fravel Vander Meer. (2000). Pushing the limits: creative web use in libraries related to instruction. Research Strategies, 17, (2000), 237-256.

Shi, Y., Xie, W., Xu, G., Shi, R., Chen, E., Mao, Y., et al. (2003). The smart classroom: Merging technologies for 
seamless tele-education. IEEE Pervasive Computing Magazine, 2(2).

Tanyeli, N. (2009). The efficiency of online English language instruction on students'reading skills. Procedia Social and Behavioral Sciences, 1, (2009), 564-567.

Thorne, S. L. (2003). Artifacts and cultures-of-use in intercultural communication. Language Learning \& Technology, 7(2), 38-67. Retrieved September 17, 2004, from http://lt.msu.edu/vol7num2/thorne/default.html

Toyoda, E., \& Harrison, R. (2002). Categorization of text chat communication between learners and native speakers of Japanese. Language Learning \& Technology, 6(1), 82-99.

Uzunboylu, H. (2005). The Effectiveness of Web Assisted English Language Instruction on the Achievement and Attitude of Students. ERIC Abstract.

Warner, C. N. (2004). It's just a game, right? Types of play in foreign language CMC. Language Learning \& Technology, 8(2), 69-87.

Wilson, T. F. (1995). The Internet at Eagan High School. T.H.E. Journal, 22(9), 75-79.

Zimmer, J. E. (2003). Teaching effectively with multimedia. Visionlearning (pp. 47-55). Retrieved from http://www.visionlearning.com/library/ 